\title{
A Book to Inspire the Pursuit of Mystery and Enchantment in HCI
}

Tuck Wah Leong, University of Technology Sydney

A year ago, on a lazy Sunday, I found a copy of Jung's Synchronicity: An Acausal Connecting Principle [1] in a box of books that a recently retired colleague gave me. I laughed out loud. Sure, I was surprised to discover that my colleague might have been interested in synchronicity, but for me, finding the book felt like a very personal message. That moment spoke directly to what I had been mulling over for a few months: whether I should resurrect my research on serendipity and related phenomena such as synchronicity.

While marveling at this synchronistic encounter, I noticed a new post on my Facebook feed. One of my research collaborators in Taiwan had just posted a photo of a book he was reading - a book about synchronicity. I was delighted! This meaningful coincidence was yet another moment of synchronicity. I had discussed research projects about the Internet of Things (IoT) with this collaborator, but we had never shared our interests in synchronicity. This sparked an idea: I should revive my research into phenomena that are fueled by chance, coincidence, and randomness. But I also suddenly realized the potential of combining the two: synchronicity and the IoT. I began rereading Jung's book, this time with a more specific aim.

One challenging (and intrinsic) point that Jung makes in the book is that truly understanding and appreciating synchronicity requires a fundamental shift in how we behold the world. We have to abandon any deterministic, mechanistic view of the universe and instead view reality as an organic whole. In fact, Schopenhauer suggests that synchronicity implies a world in which all things are inextricably woven together in the "most wonderful preestablished harmony."

This means that design efforts in HCI to support synchronicity may require approaches that not only reveal some of those inextricable and personally meaningful connections to people but also, more daringly, allow people glimpses into their connections to this preestablished order. I believe that such ambitions are very plausible today given the access to an abundant raw ingredient for synchronicity: data. More important, much of this data is rich-snapshots of people's personal and social lives from which we can glean their activities, contexts, movements, bodily states, thoughts, preferences, and routines. This pace and amount of data will only accelerate with the growth of the IoT. Such rich data can serve as a resource for design. For example, by drawing upon the capabilities of data mining, machine learning, and AI, individuals could be presented or afforded encounters with "bits" that are increasingly pertinent and appropriate, and of greater fidelity for them to make synchronistic connections. In such a future, potentially personally meaningful bits, previously unnoticed or even unimaginable, can be highlighted, nudging individuals to make synchronistic connections.

Jung chronicles many accounts of synchronicity where these moments are experienced as magical, mysterious, and potentially transformative. Designing ways to encourage people toward synchronicity will also mean potentially supporting enchantment and delight, reflection, awareness, and creative sparks. The benefits seem limitless. However, many in 
$\mathrm{HCI}$ are also rightly concerned when we work with such abundant data. While it is indeed a challenge to design ways to support the mystery, enchantment, and transformative potential of synchronicity, perhaps the greater challenge to HCI is how we can do so in ways that are also respectful and mindful of privacy.

If I could wave a magic wand over HCI, I would add a focus on supporting synchronicity through ethical explorations of the IoT without introducing new risks to privacy.

\section{Endnotes}

1. Jung, C.G. Synchronicity: An Acausal Connecting Principle. Princeton Univ. Press, Princeton, NJ, 1973.

Tuck Wah Leong is a human-computer interaction (HCI) and interaction design researcher who specializes in human-centered approaches of inquiry and technology design at the University of Technology, Sydney (UTS), Australia. tuckwah.leong@uts.edu.au 